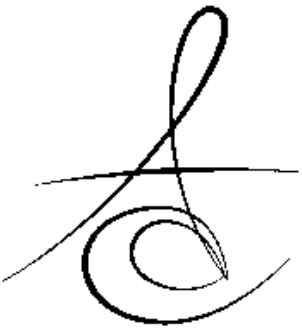

\title{
BASAMAK TİPİ VE KONİKLİK AÇISININ LİTYUM DİSİLİKAT CAM SERAMİKLERİN BASKI DAYANIMINA ETKİSİNİN DEĞERLENDİRİLMESİ
}
EVALUATION OF THE EFFECT OF MARGINAL DESIGN AND TAPER ANGLE ON THE FRACTURE STRENGTH OF LITHIUM DISILICATE GLASS CERAMICS

\author{
Dr. Öğr. Üyesi Hatice ÖZDEMİR*
}

\author{
Prof. Dr. Lütfü İhsan ALADAĞ ${ }^{* *}$
}

\begin{abstract}
Makale Kodu/Article code: 3696
Makale Gönderilme tarihi: 24.05.2018

Kabul Tarihi: 10.10 .2018
\end{abstract}

\section{öz}

Amaç: Bu çalışmanın amacı, farklı basamak tipi ve koniklik açısının lityum disilikat cam seramiklerin baskı dayanımına olan etkisini değerlendirmektir.

Gereç ve Yöntem: Baskı dayanıkılığı testi için farklı basamak tipi (chamfer ve shoulder) ve 2 farklı koniklik açısında ( $6^{\circ}$ ve $12^{\circ}$ ) 40 adet metal day hazırlandı. Metal day üzerine IPS e.max Press örnekler simante edildikten sonra baskı testi uygulandı.

Bulgular: Veriler Varyans analizi (ANOVA) ile değerlendirildi ve sonuçlar istatistiksel olarak önemli bulunmuştur $(p=0.00) .12^{\circ}$ konik açilı shoulder basamak tipli örnekler en yüksek (3534.40 $\pm 159.50 \mathrm{MPa})$, $6^{\circ}$ konik açılı chamfer örnekler ise en düşük (2281.28 $171.31 \mathrm{MPa}$ ) baskı dayanımı değerlerini göstermiştir.

Sonuç: Koniklik açısı ve basamak tipinin farklı olması IPS e.max Press' in baskı dayanımını etkilemektedir.

Anahtar Kelimeler: Lityum disilikat cam seramik, baskı dayanımı, basamak, koniklik açısı

\section{GİRİ̧̧}

Preslenebilen seramikler üretim kolaylığı, marjinal bütünlük, yarı şeffaflık, üstün mekanik özellikler, presleme ile net bir formun oluşturulması gibi birçok nedenle dental restoratif sistemin en popüler ürünlerindendirler. ${ }^{1}$ IPS e.max Press kırılma dayanımları ile çiğneme sırasında basıncın çok geldiği posterior bölge restorasyonlarında tercih sebebi olmuştur. Kırılma dayanıklıığı $400 \mathrm{MPa}$ dır. 2,3

Diş preparasyonu ve marjinal basamak dizaynı protetik restorasyonlarda kullanılan materyallerin

\section{ABSTRACT}

Aim: The aim of this study was to evaluate the effect of different margin designs and taper angel on fracture strength of lithium disilicate glass ceramics.

Materials and Methods: A total of 40 metal die samples with different margin designs (shoulder and chamfer) and two different taper angel $\left(6^{\circ}\right.$ ve $\left.12^{\circ}\right)$ were prepared for fracture strength test. Fracture force was applied after IPS e.max Press samples was cemented to the metal dies.

Results: The data were analyzed with ANOVA and the results were statistically significant $(p=0.00)$.. The samples with $12^{\circ}$ taper angle and shoulder margin design showed the highest fracture strength $(3534.40 \pm 159.50 \mathrm{MPa})$, the samples with $6^{\circ}$ taper angle and chamfer margin design showed the lowest fracture strength (2281.28 $\pm 171.31 \mathrm{MPa})$.

Conclusion: Different taper angle and margin design effect the fracture strength of IPS e.max Press.

Keywords: Lithium disilicate glass ceramic, fracture strength, margin design, taper angle

kırılma dayanımında önemli rol oynar. Preparasyon sırasında oluşturulan basamak, çiğneme kuvvetinin dişe dengeli dağılmasını sağlarken, kronun statik dayanıklılığını da arttırır. Tam seramik restorasyonlarda dayanıklılığın sağlanabilmesi için restorasyonun belirli bir kalınlıkta olması gerekir. Bu durum, yeterli ve dengeli diş preparasyonunun gerekliliğini ortaya koymaktadır. $^{2}$

Tam seramik sistemlerin sağlıklı bir şekilde uygulanabilmesi için diş preparasyonunun biyomekanik ilkelerine dikkat edilmesi gerekir. Bu ilkelerden

*Atatürk Üniversitesi, Diş Hekimliği Fakültesi, Protetik Diş Tedavisi AD, Erzurum.
** Emekli


özellikle, tutuculuk ve direnç tam seramik sistemlerin uzun dönem başarısında oldukça etkilidir. Restorasyonun giriş yolundan ya da uzun ekseninden ayrılmasını önleyen özellik olan tutuculuk, diş preparasyonu sırasında hekimin kontrolündeki dört faktörden etkilenir. Bunlar; koniklik açısı, simanın toplam yüzey alanı, makaslama stresleri altındaki siman bölgesi ve diş yüzeyinin pürüzlülüğü' dür. ${ }^{4}$

Koniklik açıSı, diş preparasyonunun karşıt iki duvarı arasındaki ilişkiyi ifade eder. Preparasyonun bir duvarının o preparasyonun uzun aksı ile olan ilişkisi de o duvarın eğimidir. ${ }^{5}$ Teorik olarak en iyi tutuculuğu sağlamak için preparasyonun duvarları birbirine mümkün olduğunca paralel olmalıdır. Bununla birlikte; undercutlardan kaçınmak için ve simantasyon sırasında restorasyonun tam oturumuna izin vermek için duvarlar biraz koniklik açısına sahip olmalıdır. $2^{\circ}$ ila $6.5^{\circ}$ arasındaki koniklik ideal olarak düşünülür. ${ }^{4}$

Sabit protezlerin başarısında ya da başarısızlığında büyük oranda rol oynayan bir diğer faktör de dişeti kenarı uyumudur. Bunun önemini vurgulayan Shillinburg ve arkadaşları "Oral kavitenin biyolojik ortamında restorasyonun uzun ömürlü olabilmesi, sadece sabit protez kenarının diş kesiminin bitiş çizgisine sıkıca adapte olması ile sağlanır" demektedirler. ${ }^{5}$ Preparasyonun bitiş çizgisinin konfigürasyonu restoratif materyalin marjindeki hacmini ve şeklini belirler ve ayrıca restorasyonun oturumunu ve marjinal adaptasyonunu etkiler. ${ }^{6}$ Marjinal dizayn 3 temel tipte sınıflandırılabilirler. Bunlar; künt basamak kesimi (Shoulder -bizotajlı shoulder), oluk biçimli marjinal sınır (Chamfer- bizotajlı chamfer) ve bıçak sırtı (Knife edge)'dır. ${ }^{5}$ Bu basamak tiplerini, özellikle üst çene arka bölgede uygulamak oldukça zordur. ${ }^{7}$

Mekanik dayanıklılık restorasyonların klinik başarısının tespitinde önemli bir faktördür. ${ }^{8}$

Çiğneme kuvvetlerinin çoğu baskı şeklinde olduğu için baskı dayanıklılığı özellikle çiğneme işleminde önemlidir. Baskı dayanıklıı̆ı, çekme kuvvetlerinde zayıf ve kırılgan materyallerin kıyaslanması için oldukça etkilidir. $^{9}$

Bu çalışmada, farklı basamak tipleri ve koniklik açılarında hazırlanan metal day' lar üzerine yapıştırılan IPS e.max Press örneklerin baskı dayanımı değerlendirildi. Çalışma hipotezi, farklı basamak tipi ve koniklik açılarının IPS e.max Press örneklerin baskı dayanımını etkileyeceğidir.

\section{GEREÇ VE YÖNTEM}

40 adet paslanmaz çelik metal day oklüzogingival uzunlukları $4 \mathrm{~mm}$ olacak şekilde ${ }^{10}$ iki tip marjinal dizayn (Chamfer ve Shoulder) ${ }^{5,11,12}$ ve iki çeşit koniklik açısında $\left(6^{\circ}\right.$ ve $\left.12^{\circ}\right)$ tornada hazırlandı. Chamfer ve shoulder basamakların redüksiyon kalınlığı $1.0 \mathrm{~mm}$ olarak belirlendi. ${ }^{10,12} \mathrm{Bu}$ iki gruptaki day' lar daha sonra kendi aralarında her grupta 10 örnek olacak şekilde 4 alt gruba ayrıldı (Şekil.1).

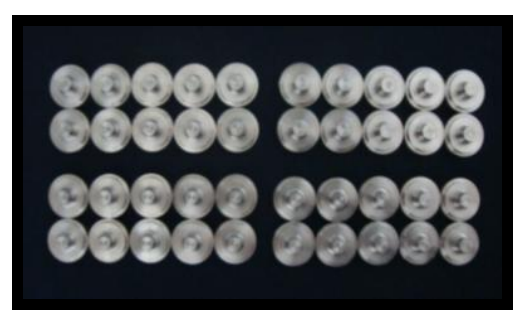

Şekil 1. Çalışmada kullanılan metal day' lar

Metal day' ların üzerine yapılacak tam seramik kor materyallerinin standart boyutlarda olması için yine tornada özel bir kalıp hazırlandı. Bu kalıbın day'a doğru ve sıkı bir şekilde oturmasını sağlamak için day etrafında bir basamak yapıldı. Kalıp içindeki çıkıntılı kısım bu basamağa oturmaktadır (Şekil.2). Kalıbın üst sınırı ile prepare edilen metal day' ların oklüzal yüzeyi arasında $1 \mathrm{~mm}$ ' lik boşluk bırakılarak örneklerin oklüzal kalınlıklarının $1 \mathrm{~mm}$ olması sağlandı. Metal day' ların ve kalıbın yapımından sonra seramik kor örneklerinin yapım aşamasına geçildi.

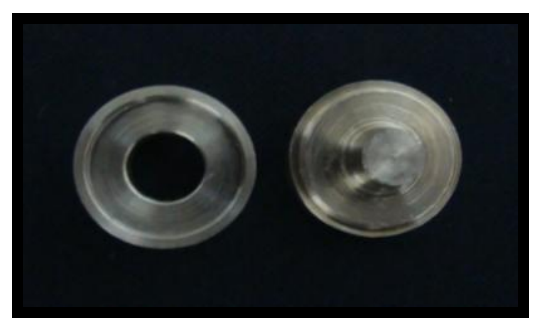

Şekil 2. Metal day ve üzerine hazırlanan kalıp

Metal day' ın üzerine iki kat day spacer basamaklardan 0,5 $\mathrm{mm}$ uzaktan olacak şekilde sürülerek kuruması beklendi. Mum modelajın kolay çıkması için ince bir tabaka izolasyon maddesi day spacer'ın ve metal kalıbın iç yüzeylerine bir fırça vasıtasıyla sürüldü. Daha sonra kalıp, day üzerine yerleştirildi. Özel empress mumu ısıtılarak kalıbın üst kısmındaki boşluktan döküldü ve mumun seviyesi kalıbın üst kısmı ile sıfırlandı. Mum soğumaya bırakıldı.

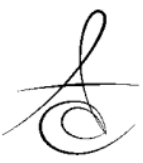


$\mathrm{Bu}$ şekilde mum modelajların oklüzal kalınlığı $1 \mathrm{~mm}$ olarak hazırlanmış oldu. Daha sonra modelaja zarar vermeden kalıp metal day'ın üzerinden alındı ve modelaj metal day' dan ayrıldı. Bu şekilde mum modelajlar tamamlandı. Hazırlanan mum modelajlar üretici firmanın önerileri doğrultusunda IPS e.max Press (Ivoclar Vivadent, Zurich, Switzerland) örneklere dönüştürüldü. Örneklerin pasif olarak day' larına oturması için iç uyumlamaları elmas frezlerle yapıldı. Düzeltmeler yapıldıktan ve day' larla uyumlarından emin olunduktan sonra, seramik örnekler 15 dakika ultrasonik temizleyicide tutularak üzerindeki artıklardan temizlendi ve dişler üzerine simante edilmek için hazır hale getirildi (Şekil.3).

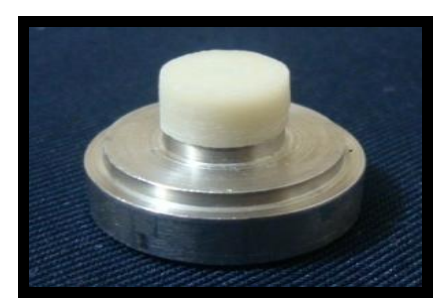

Şekil 3. Metal day üzerine hazırlanan IPS e.max Press örneğin bitmiş hali

Seramik örneklerin metal day' lara simantasyonunda Panavia F 2.0 dual-cure resin siman (Kuraray Noritake Dental Inc., Tokyo, Japan) kullanıldı. Öncelikle, metal day' ların yüzeyi aseton ile silinip, yıkandı ve basınçlı hava ile kurutuldu. Kurutulmuş metal yüzeyine bir fırça ile Alloy Primer sürülerek 15 saniye bekletildi ve kurutuldu. Clearfil Porcelain Bond Activator ve Clearfil SE Bond Primer (Kuraray Medical Inc., Okayama, Japan) eşit miktarda karıştırılarak metal yüzeyine fırça ile sürülüp 10 saniye bekletildi ve kurutuldu. Clearfil SE BOND Bond sürülüp fazlalıkları hava ile uzaklaştırıldı ve 10 sn ışın cihazıyla ışınlandı. Daha sonra, IPS e.max Press kor örneklerin iç yüzeyi hidroflorik asit (Bisco Porcelain Etchant ( $9.5 \%$ HF), Bisco, Inc., Schaumburg, USA) ile 20 saniye pürüzlendirildi. Asiti nötralize etmek için daha sonra 20 saniye basınçlı su altında yıkandı ve kurutuldu. Tüm seramik örneklerin iç yüzeyine Clearfil Porcelain Bond Activator ve Clearfil SE Bond Primer eşit miktarda karıştırılarak fırça ile sürülüp 10 saniye bekletildi ve kurutuldu. Clearfil SE BOND Bond ince bir tabaka halinde seramik iç yüzeylerine sürülüp fazlalıkları hava ile uzaklaştırıldı ve 10 sn ışın cihazıyla ışınland.
Son olarak, Panavia F 2.0.' In eşit miktarda base ve katalizörü karıştırılarak seramik örneklerin içerisine yerleştirilerek metal day üzerine parmak basıncı ile oturtuldu. Taşan siman bir fırça yardımıyla marjinden alındı. Daha sonra sabit basınç altında polimerizasyonlarını sağlamak için şeffaf selüloz bir bant kapatılıp örnek üzerine $400 \mathrm{gr}$ standart ağırlık tatbik edildi. $\mathrm{Bu}$ yük altında restorasyonun tüm yüzeylerinden 20 saniye $550 \mathrm{mw} \backslash \mathrm{cm}^{2}$ ışık şiddetine sahip LED ışık cihazı uygulanarak polimerizasyon yapıldı. Oksijen ile teması kesmek için marjinal kenarlarına likit Oxyguard (Oxyguard II; Kuraray Noritake Dental Inc.) sürüldü. Siman sertleştikten sonra ince grenli elmas frezlerle marjindeki artık siman temizlendi ve bu bölgelerin porselen lastikleri ile polisajı yapıldı. Daha sonra simantasyonu tamamlanan tüm örnekler oda ısısında 24 saat distile suda bekletildi.

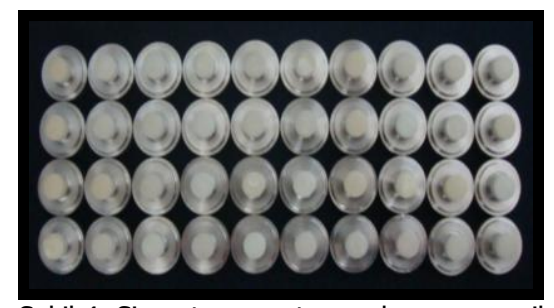

Şekil 4. Simantasyonu tamamlanan seramik örnekler

Simantasyonları tamamlanan örneklerin kırılma dirençlerinin tespiti için baskı dayanıklıı̆ı testi yapıldı. $\mathrm{Bu}$ test için Universal Test Cihazı (Instron, Model 2710-003; Instron Corp., Norwood, MA) kullanıldı. Metal day' lar test cihazına özel bir düzenek ile sabitlendi. Seramik örneklerin orta noktası işaret kalemiyle belirlendi. Baskı kuvveti uygulaması için özel olarak hazırlatılan $2 \mathrm{~mm}$ kalınlığındaki uç örneklerin tam ortasına yerleştirilerek yükün örneğin uzun aksı boyunca uygulanması sağlandı (Şekil.5). $0.5 \mathrm{~mm} / \mathrm{dk}$ başlık hızı ile bu noktadan örneklere kuvvet uygulandı. Seramik korların kırıma anındaki değerleri MPa cinsinden kaydedildi.

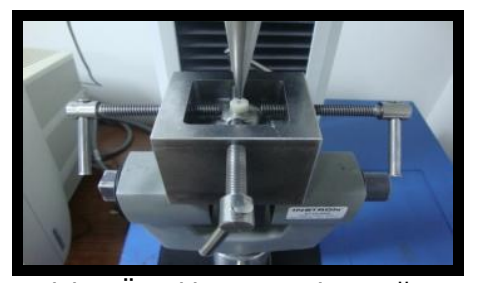

Şekil 5. Örneklerin test düzeneğine ve test cihazına yerleştirilmesi 


\section{BULGULAR}

Elde edilen veriler varyans analizi ile değerlendirildi (Tablo.1) Analiz sonucunda marjinal dizayn ve koniklik açılarının kendi aralarındaki ve marjinal dizayn-koniklik açısı arasındaki etkileşim istatistiksel olarak önemli bulunmuştur $(p<0.05)$.

Tablo 1. Baskı dayanıklığı testi için Varyans analizi sonuçları

\begin{tabular}{|l|l|c|c|c|}
\hline Varyans Kaynağı & Sd & KO & F & P \\
\hline Marjinal dizayn & 1 & 8491456.63 & 265.927 & 0.00 \\
\hline Koniklik açıSı & 1 & 1099791.20 & 34.44 & 0.00 \\
\hline $\begin{array}{l}\text { Marjinal } \\
\text { dizayn*Koniklik açıSı }\end{array}$ & 1 & 145663.18 & 4.56 & 0.04 \\
\hline Hata & 36 & 31931.53 & & \\
\hline
\end{tabular}

Varyans analizi sonucunda IPS e.max Press örneklerde hazırlanan shoulder ve chamfer basamak tiplerinin baskı dayanımı değerleri arasındaki fark istatistiksel olarak önemli bulunmuştur. $(p<0.05)$ Baskı dayanıklılığı değerlerinin ortalamalarına bakıldığında shoulder marjinal dizaynının baskı dayanımı değeri (3308.24 $288.68 \mathrm{MPa}$ ) chamfer marjinal dizaynının baskı dayanımı değerinden $(2386.75 \pm 206.69$ MP) daha yüksek tespit edilmiştir.

Varyans analizine göre IPS e.max Press örneklerde hazırlanan farklı koniklik açılarının baskı dayanımı değerleri arasındaki fark istatistiksel olarak önemli bulunmuştur. $(p<0.05) 12^{\circ}$ konik açlı metal day üzerine yapılan IPS e.max Press örneklerin baskı dayanımı değerleri (3013.31 \pm 561.24$) 6^{\circ}$ konik açılı örneklerinkinden $(2681.68 \pm 447.33)$ yüksek olarak tespit edilmiştir.

Yapılan Varyans analizine göre marjinal dizayn ile koniklik açısı arasındaki interaksiyon da istatistiksel olarak önemli bulunmuştur. $(p<0.05)$

IPS e.max Press seramik örneklerin 2 farklı marjinal dizayn ve iki farklı koniklik açısında gösterdikleri baskı dayanımı değerlerine ait ortalama, standart sapma, minimum ve maksimum değerleri Tablo.2' de verilmiştir.
Tablo 2. IPS e.max Press örneklere ait baskı dayanımı değerleri

\begin{tabular}{cccccc}
\hline $\begin{array}{c}\text { Basamak Koniklik Ortalama Standart } \\
\text { Tipleri } \\
\text { Açlları }\end{array}$ & $\begin{array}{c}\text { Max. } \\
\text { Sapma }\end{array}$ & $\begin{array}{c}\text { Min. } \\
\text { Değer } \\
\text { (MPa) }\end{array}$ & $\begin{array}{c}\text { Değer } \\
\text { (MPa) }\end{array}$ \\
\hline Shoulder & $\mathbf{6}^{\circ}$ & 3082.08 & 191.89 & 3342.95 & 2719.89 \\
& $\mathbf{1 2}^{\circ}$ & 3534.40 & 159.50 & 3750.48 & 3247.58 \\
& Genel $^{\circ}$ & 3308.24 & 288.68 & & \\
\hline \multirow{2}{*}{ Chamfer } & $\mathbf{6}^{\circ}$ & 2281.28 & 171.31 & 2560.62 & 2056.59 \\
& $\mathbf{1 2}^{\circ}$ & 2492.22 & 190.04 & 2787.94 & 2175.97 \\
& $\mathbf{G e n e l}^{\circ}$ & 2386.75 & 206.69 & & \\
\hline \multirow{3}{*}{ Toplam } & $\mathbf{6}^{\circ}$ & 2681.68 & 447.33 & & \\
& $\mathbf{1 2}^{\circ}$ & 3013.31 & 561.24 & & \\
& $\mathbf{G e n e l}^{\circ}$ & 2847.50 & 528.34 & & \\
\hline
\end{tabular}

*Değerler MPa cinsinden verilmiştir.

$12^{\circ}$ konik açılı shoulder marjinal dizayn en yüksek baskı dayanımı değerini (3534.40 159.50 $\mathrm{MPa}$ ) gösterirken en düşük bağlanma dayanımı değerini (2281.28 $\pm 171.31 \mathrm{MPa}$ ) ise $6^{\circ}$ konik açılı chamfer marjinal dizayn göstermektedir. Shoulder marjinal dizaynının genel baskı dayanımı değeri (3308.24 $\pm 288.68 \mathrm{MPa})$ chamfer marjinal dizaynının genel baskı dayanımı değerinden (2386.75 \pm 206.69 $\mathrm{MPa}$ ) oldukça yüksek bulunmuştur. $12^{\circ}$ konik açılı örneklerin göstermiş olduğu baskı dayanımı değeri (3013.31 $561.24 \mathrm{MPa}) 6^{\circ}$ konik açılı örneklerin göstermiş olduğu baskı dayanımı değerinden (2681.68 $\pm 447.33 \mathrm{MPa}$ ) yüksek bulunmuştur.

Farklı marjinal dizayn ve koniklik açısındaki iç önemlilik durumları t-testine göre analiz edilmiştir. Yapılan analiz sonucunda koniklik açıları ve basamak tipleri arasındaki fark istatistik olarak önemli bulunmamıştır. $(p<0.05)$

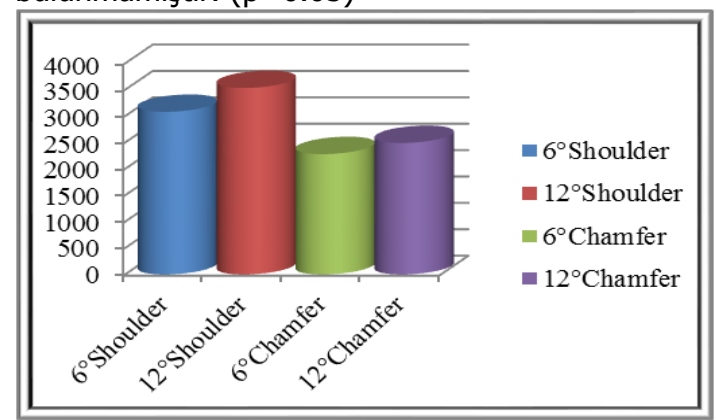

Şekil 6. Farklı koniklik açısı ve basamak tiplerine bağlı olarak IPS e.max Press örneklerin baskı dayanımının karşılaştırıması

\section{TARTIŞMA}

Çalışma sonucu elde edilen veriler çalışma hipotezini desteklemektedir. Farklı basamak tipi ve

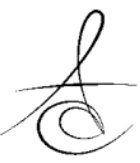


koniklik açıları lityum disilikat cam seramiklerin baskı dayanımını etkilemektedir. Çalışma sonucu elde edilen verilere göre, $12^{\circ}$ konik açılı shoulder marjinal dizayna sahip örnekler en yüksek baskı dayanımını gösterirken; $6^{\circ}$ chamfer marjinal dizayna sahip örnekler en düşük baskı dayanımını göstermiştir. Koniklik açısı arttıkça baskı dayanımı da artmaktadır. Bu durum, kullanılan materyalin kalınlığının artmasından kaynaklanabilir. Ayrıca, shoulder marjinal dizayna sahip örnekler chamfer marjinal dizayna sahip örneklerden daha büyük baskı dayanımı değerleri göstermiştir. Bu durum, marjinal bölgede artan materyal kalınlığından ve bu bölgeye gelen kuvvetlerin metal dayların uzun aksına paralel olarak iletilmesinden kaynaklanabilir.

Kırıma dayanımı, marjinal uyum ve estetik tam seramik restorasyonlar için önemli özelliklerdir. ${ }^{13}$ Hastaların estetiğe olan taleplerinin artması, anterior bölgelerde olduğu kadar posterior bölgelerde de tam seramik restorasyonların kullanımını arttırmıştır. ${ }^{14}$ Ancak, tam seramik sistemler çekme ve bükülme stresleri altında zayıf ve kırılgandırlar. ${ }^{15}$

Tam seramik restorasyonlar özellikle posterior bölgelere yerleştirildiklerinde kırılmaya meyilleri daha da artar. Posterior bölgedeki restorasyonlar yüksek çiğneme kuvvetlerini tolere etmelidir. Fiziksel maksimum posterior çiğneme kuvvetleri, fasial morfoloji ve yaşa bağlı olarak $880 \mathrm{~N}^{\prime}$ un üzerindeki değerlere çıkabilir. ${ }^{16}$ Molar dişler, anterior ve premolar üzerine yapılan restorasyonlara göre daha fazla başarısızlık riski oluştururlar. ${ }^{17}$

Çalışmada, anterior bölgenin yanında posterior bölgede de estetik taleplerin artmasından dolayı, bu dişlerin üzerine yapılacak tam seramik kronların baskı dayanımı incelenmiştir. Seramiklerin dayanıklıı̆ı̆; tam seramik kron sistemleri ${ }^{18,19}$, porselen kronların kalınlığı ${ }^{19,20}$, seramik içindeki çatlağın dağılımı, test metodu ${ }^{19}$, yapım tekniği, restorasyonun yüzey bitimi, yapıştırma metodu ${ }^{21,22}$ ve preparasyon dizaynı ${ }^{23,24}$ gibi faktörlerden etkilenebilir. Diş preparasyonu, bu kırılgan yapıdaki tam seramik restorasyonlar için çok önemli bir aşamadır. ${ }^{25}$ Preparasyonun temel amaçlarından birisi restoratif materyale destek olabilecek bir diş redüksiyonu sağlamaktır. Tam seramik kronlar ancak yeterli kron kalınlığında estetik ve dayanıklııı açısından tatmin edici olabilirler. ${ }^{25} \mathrm{Bu}$ nedenle, çalışmada diş redüksiyonunun etkisini görmek için $6^{\circ}$ ve $12^{\circ}$ koniklik açıları tercih edilmiştir.
Posterior seramik restorasyonlar için önerilen diş preparasyon dizaynları geleneksel döküm metal restorasyon dizaynlarına benzerdir; fakat posterior seramik restorasyon preparasyonunda daha fazla oklüzal diş redüksiyonu ve biraz daha artmış koniklik açısı vardır. ${ }^{26} \mathrm{Bu}$ preparasyonlar diş yapısından çok kesim gerektirebilirler ${ }^{27}$ ve daha fazla diş yapısı kaldırıldığı için diş kırılmaya karşı daha az dirençli hale gelir. ${ }^{28}$

Diş kesimi sırasında oluşturulan basamak, çiğneme kuvvetlerinin dişe dengeli dağılmasını sağlarken, kronun statik gücünü de arttırır. ${ }^{10}$ Oklüzal temaslar sırasında stres yoğunlaşmasının olduğu bölge servikal bölgedir. Bu nedenle protetik tedavi amacıyla yapılan tam seramiklerin diş kesiminde basamak şekli gerilim dağııııında önemli rol oynamaktadır. ${ }^{29}$ Yapılan çalışmalar, basamak şekillerine bağlı olarak meydana gelen stres birikimlerinin bu alanlarda önem kazandığını göstermektedir. ${ }^{26,30,31}$ Ayrıca preparasyonun marjinal uyum üzerindeki etkisi de önemlidir. Oral kavitenin biyolojik ortamında restorasyonun uzun ömürlü olabilmesi için sabit protez kenarının diş kesiminin bitiş çizgisine sıkıca adapte olması gerekmektedir. ${ }^{6}$

Hem shoulder hem de chamfer bitiş çizgisi tam seramik kronlar için seçilebilen marjinal dizaynlardır. ${ }^{10}$ Shoulder marjinal dizayn kuvvetin köke iletimini en iyi şekilde sağlar. ${ }^{6}$ Oklüzal kuvvetlere direnci arttırır ve porselende kırıklara neden olabilecek stresleri minimalize eder. Sağlıklı restorasyon konturları ve maksimum estetik için alan oluşturur. ${ }^{5}$ Aynı şekilde chamfer marjinal dizayn ile de yeterli kenar kalınlığında ve sağlamlıkta restorasyonlar elde edilebilmektedir. ${ }^{6}$ Chamfer marjinal dizaynının uygun frezler ile oluşturulması oldukça kolaydır ve prepare edilmiş diş, ölçü ve day üzerinde kolaylıkla izlenebilmektedir. ${ }^{10}$ Çalışma sonucu elde edilen veriler bu durumu desteklemektedir. Shoulder marjinal dizayna sahip örnekler chamfer marjinal dizayna sahip örneklerden daha yüksek baskı dayanımı göstermiştir.

Restorasyonların artan koniklik açısının tutuculuk ve direnci nasıl etkilediği ile ilgili pek çok çalışma yapılmasına rağmen, artan koniklik açısının tam seramik kronların kırıma dayanımına etkisi üzerine fazla çalışma bulunmamaktadır. Klinik çalışmalar preparasyonların koniklik açısının tutarlı olmadığını ve idealden sapmalar olduğunu bildirmiştir. ${ }^{32,33} 2^{\circ}$ ila $6.5^{\circ}$ arasındaki koniklik açısı ideal olarak düşünülür. Bu 
çalışmada da, ideal kabul edilen $6^{\circ}$ konik açısı ile idealden daha fazla olan $12^{\circ}$ konik açıları tercih edilmiştir. Sonuçta, $12^{\circ}$ konik açıya sahip örnekler daha fazla baskı dayanımı göstermiştir. Bu durum, artan seramik materyal kalınlığından kaynaklanabilir.

Çeşitli tam seramik restorasyonların baskı dayanımını inceleyen çalışmalarda farklı marjinal dizayn ve koniklik açıları kullanılmıştır. Yavuz ve arkadaşları $^{34}$ IPS Empress, In-Ceram ve Biofibral tam seramik kronların dayanıklılı̆ını inceledikleri çalışmalarında premolar dişi taklit edecek şekilde pirinçten yapılmış day' lar üzerinde 1,3 mm genişliğinde chamfer marjinal dizayn, $4^{\circ}$ aksiyel konik açısı ve $7 \mathrm{~mm}$ kron uzunluğu oluşturmuşlardır.

Komine ve arkadaşlarının ${ }^{15}$ In-Ceram Alumina restorasyonların posterior bölgedeki kırıma dayanımını inceledikleri çalışmalarında maksiller birinci molar dişler kullanmışlardır. Marjinal dizayn 1,2 mm genişliğinde chamfer marjinal dizayndır. $4^{\circ}$ ila $6^{\circ}$ konik açısı ve 4,5 mm kron boyu kullanılmıştır.

Pallis ve arkadaşları ${ }^{11}$ maksiler birinci moların taklit edildiği rezin day'lar üzerinde Procera AllCeram, In-Ceram Zirconia ve IPS Empress 2 tam seramik kronların kırılma dayanımını inceledikleri çalışmalarında $1 \mathrm{~mm}$ genişliğinde shoulder marjinal dizaynı ve $6^{\circ}$ konik açısı kullanmışlardır. Sonuçta, farklı seramik tiplerinde farklı baskı dayanımları elde etmişlerdir.

Attia ve Kern ${ }^{35}$ iki farklı tam seramik sistemi olan IPS Empress 2 ve ProCAD' in dayanıklıı̆ını inceledikleri çalışmalarında 5 mm' lik kron uzunluğu, $1,5 \mathrm{~mm}$ genişliğinde shoulder marjinal dizaynını ve $6^{\circ}$ aksiyel konik açısına sahip maksiller premolar dişler kullanmışlardır.

Oyar ve arkadaşları ${ }^{36}$ farklı diş preparasyonu üzerine hazırlanan seramik kronlarda stres dağıımını sonlu elemanlar analizi ile değerlendirdikleri çalışmalarında anatomik olmayan diş dizaynının Empress Esthetic seramik için en uygun dizayn olduğunu bildirmişlerdir. Aynı araştırıcılar başka bir çalışmalarında da anatomik olmayan diş dizaynının porselen yapısındaki stres miktarı ve dağılımında daha avantajlı olduğunu bildirmişlerdir. ${ }^{37}$

Miura ve arkadaşları ${ }^{38}$ marjinal dizaynın farklı yapıda zirkonyum kuronlardaki stres dağıımına etkisini inceledikleri çalışmalarında yuvarlaklaştırılmış shoulder basamak ile derin chamfer basamağın oklüzal stresleri minimalize etmede en uygun marjinal dizayn olduğunu bildirmişlerdir.
Estetik ve biyouyumluluğu açısından üstün özelliklere sahip fakat kırılgan olan tam seramik kronların çiğneme kuvvetlerinin yoğun olduğu posterior bölgede çeşitli preparasyon dizaynları kullanarak dayanıkııı̆ını arttırmayı ve marjinal uyumunu maksimuma çıkarmayı amaçladığımız bu çalışmada, posterior uygulamalarda tam seramik restorasyonlar için en uygun preparasyon dizaynının elde edilmesi amaçlanmıştır. Bu amaçla posterior diş preparasyonu taklit edilerek sıklıkla kullanılan shoulder ve chamfer marjinal dizayn ve $6^{\circ}$ ve $12^{\circ}$ konik açıları arasındaki farklılık kıyaslanmıştır. Çalışmada, metal day örneklerin kullanılması ve aralarında çok fazla fark bulunan iki farklı koniklik açısının değerlendirilmesi mevcut çalışmanın limitasyonları olarak sayılabilir. Metal day yerine molar diş kullanılması ya da $6^{\circ}$ ile $12^{\circ}$ arasındaki diğer koniklik açılarının değerlendirilmesi ile farklı sonuçlar elde edilebilir. Sonuç olarak, $12^{\circ}$ konik açılı shoulder basamak tipli örneklerin en yüksek, $6^{\circ}$ konik açılı chamfer örnekler ise en düşük baskı dayanımı değerlerini gösterdiği tespit edilmiştir.

\section{SONUÇ}

Çalışma sonucu elde edilen verilere dayanarak posterior dişlere lityum disilikat cam seramik kron yapımı planlandığı zaman koniklik açısının arttırılması ve shoulder marjinal dizaynın tercih edilmesi tavsiye edilebilir

Hatice Özdemir: ORCID ID: 0000-0001-8512-0471 L.İhsan Aladağ ORCID ID: 0000-0001-7380-1472

\section{KAYNAKLAR}

1. Albakry M, Guazzato M, Swain MV. Biaxial flexural strength, elastic moduli, and x-ray diffraction characterization of three pressable all-ceramic materials. J Prosthet Dent 2003;89:374-80.

2. Bozoğulları HN. İki farklı tam seramik kor materyalinin baskı dayanıklılı̆ı ve marjinal uyumu üzerine farklı marjinal dizayn ve taper açılarının etkisi. Sağlık Bilimleri Enstitüsü, Protetik Diş Tedavisi Anabilim Dalı. Doktora tezi, Konya: Selçuk Üniversitesi, 2007.

3. Ivoclar Vivadent AG. The Compatible All-Ceramic System, Dental Technician and Instructor, Schaan, Liechtenstein, 2005. 
4. Shillingburg HT, Jacobi $R$, Brackett SE. Fundamentals of Tooth Preparations, Chicago, Quintessence Books, 1991.

5. Shillingburg HT, Hobo S, Whitsett LD, Jacobi R, Brackett SE. Fundementals of Fixed Prosthodontics. $3^{\text {th }}$ edition, London, U.K: Quintessence Publishing Co., Inc., 1997: s. 400-5, 433-52.

6. Zaimoğlu A, Can G. Sabit protezler, Ankara, A Ü Dişhek Fak Yayınları, 2004.

7. Korkmaz C. Tam seramiklerin diş hekimliğindeki yeri. J Dent Fac Atatürk Uni 2014;24:136-40.

8. Anusavice KJ. Philips' Science of Dental Materials, $11^{\text {th }}$ ed. Saunders, St. Louis: Elsevier Health Sciences; 2003:655-719.

9. Craig RG. Restorative Dental Materials, $9^{\text {th }}$ ed. Mosby, St. Louis, 1993.

10. Goodacre CJ, Campagni WV, Aquilino SA. Tooth preparations for complete crowns: An art form based on scientific principles. J Prosthet Dent 2001;85:363-76.

11. Pallis K, Griggs JA, Woody RD, Guillen GE, Miller AW. Fracture resistance of three all-ceramic restorative systems for posterior applications. J Prosthet Dent 2004;91:561-9.

12. Wood KC, Berzins DW, Luo Q, Thompson GA, Toth JM, Nagy WV. Resistance to fracture of two all ceramic crown materials following endodontics access. J Prosthet Dent 2006;95:33-41.

13. Strub JR, Beschnidt SM. Fracture strength of 5 different all-ceramic crown systems. Int J Prosthodont 1998;11:602-9.

14. Blatz MB. Long-term clinical success of all-ceramic posterior restorations, Quintessence Int 2002;33:415-26.

15. Komine F, Tomic M, Gerds T, Strub JR. Influence of different adhesive resin cements on the fracture strength of aluminum oxide ceramic posterior crowns. J Prosthet Dent 2004;92:359-64.

16. Kiliaridis S, Kjellberg H, Wenneberg B, Engstrom C. The relationship between maximal bite force, bite force endurance and facial morphology during growth. A cross-sectional study. Acta Odontol Scand 1993;51:323-31.

17. Malament KA, Socransky SS. Survival of Dicor glass-ceramic dental restorations over 14 years. Part II: Effect of thickness of Dicor material and design of tooth preparation. J Prosthet Dent 1999;81:662-7.

18. Yoshinari $M$, Derand $T$. Fracture strength of allceramic crowns. Int J Prosthodont 1994;7:329-38.

19. McLean JW. New dental ceramics and esthetics. J Esthet Dent 1995;7:141-9.

20. Anusavice KJ, Hojjatie B. Tensile stress in glassceramic crowns: Effect of flaws and cement voids. Int J Prosthodont 1992; 5:351-8.

21. Chen HY, Hickel R, Setcos JC, Kunzelmann KH. Effects of surface finish and fatigue testing on the fracture strength of CAD/CAM and pressed ceramic crowns. J Prosthet Dent 1999;82:468-75.

22. Kelly JR. Clinically relevant approach to failure testing of all-ceramic restorations. J Prosthet Dent 1999;81:652-61.

23. Knobloch L, Kerby RE, Berlin JS, Lee J. Fracture toughness of resin-based luting cements. J Dent Res 1997;76:155 (abstract 1131).

24. Mendonca JS, Gomes JEF, Franca MTC, Lauris JRP, Navarro MFL. Diametral tensile strength of conventional and resin-modified glass-ionomer luting cements. J Dent Res 1997;76:318 (abstract 2440).

25. De Jager $\mathrm{N}$, De Kler M, Van Der Zel JM. The influence of different core material on the FEAdetermined stress distribution in dental crowns. Dent Mater 2006;22:234-42.

26. Etemadi S, Smales RJ, Drummond PW, Goodhart JR. Assessment of tooth preparation design for posterior resin-bonded porcelain restorations. J Oral Rehabil 1999;26:691-7.

27. Moscovich $\mathrm{H}$, Creugers $\mathrm{NH}$, Jansen JA, Wolke JG. Loss of sound tooth structure when replacing amalgam restorations by adhesive inlays. Oper Dent 1998;23:327-31.

28. Soares CJ, Martins LRM, Fonseca RB, CorrerSobrinho L, Neto AJF. Influence of cavity preparation design on fracture resistance of posterior leucite-reinforced ceramic restorations. J Prosthet Dent 2006;95:421-9.

29. Güngör $M A$, Dündar $M$, Karaoğlu Ç, Sonugelen $M$, Artunç C. Tam seramik malzemelerde basamak şeklinin gerilim dağıımına etkisi: Sonlu elemanlar stres analizi. Ege Üniv Dişhek Fak Derg 2005;26:145-53. 
30. Butel EM, Campell JC, DiFiore PM. Crown margin desig: A dental school survey. J Prosthet Dent 1991;65:303-5.

31. Ohyama T, Yoshinari M, Oda Y. Effect of cyclic loading on the strength of all-ceramic materials. Int J Prosthodont 1999;12:28-37.

32. Parker $\mathrm{MH}$, Malone $\mathrm{KH}$, Trier $\mathrm{AC}$. Evaluation of resistance form for prepared teeth. J Prosthet Dent 1991;66:730-3.

33. Trier AC, Parker MH, Cameron SM. Evaluation of resistance form of dislodged crowns and retainers. J Prosthet Dent 1998;80:405-9.

34. Yavuz Ö, Toksavul S, User A. Tüm seramik kronların kırılma dayanıklııklarının seramometal restorasyonlarla karşılaştırıması. Ege Üniv Dişhek Fak Derg 1999;20:102-10.

35. Attia $A$, Kern M. Influence of cyclic loading and luting agents on the fracture load of two allceramic crown systems. J Prosthet Dent 2004;92:551-6.

36. Oyar P, Ulusoy M, Eskitaşçıŏlu G. Finite element analysis of stress distribution in ceramic crowns fabricated with different tooth preparation designs. J Prosthet Dent 2014;112:871-7.

37. Oyar P, Ulusoy M, Eskitaşçıoğlu G. Finite element analysis of stress distribution of 2 different tooth preparation designs in porcelain-fused-to-metal crowns. Int J Prosthodont. 2006;19:85-91.

38. Miura S, Kasahara S, Yamauchi S, Egusa H. Effect of finish line design on stress distribution in bilayer and monolithic zirconia crowns: a threedimensional finite element analysis study. Eur J Oral Sci 2018;126:159-65.

\section{Yazışma Adresi}

Dr. Öğr. Üy. Hatice ÖZDEMİR

Atatürk Üniversitesi, Diş Hekimliği Fakültesi, Protetik Diş Tedavisi $A D$, Erzurum TIf: 04422311783

e-mail: dentist_hatice@hotmail.com 